\title{
A (SOBRE)VIDA DO POSITIVISMO JURÍDICO
}

\author{
Lucas Duarte de Medeiros ${ }^{338}$
}

Recebido em: 29/11/2016

Aprovado em: 20/05/2017

\begin{abstract}
RESUMO
$\mathrm{O}$ trabalho tem a pretensão de analisar se o advento do neoconstitucionalismo implicou na superação total do positivismo jurídico, como parte da doutrina brasileira costuma afirmar. Muito dessa problemática está ligada à imprecisão semântica que ronda os dois termos: positivismo jurídico e neoconstitucionalismo. Balizando corretamente o uso das expressões, expõe-se sinteticamente a evolução desta corrente filosófica por meio do pensamento de seus principais defensores, para, após, discorrer sobre a crítica a ela empreendida por Ronald Dworkin, precursor do pós-positivismo. Demonstrar-se-á que Dworkin foi confrontado com respostas à altura por correntes de diferentes matizes que buscam adequar aquela filosofia do direito ao contexto histórico atual, dando origem a escola conhecida como neopositivismo. Conclui-se, portanto, que o positivismo jurídico sobrevive no período neoconstitucional e deve ser prestigiado no debate jurídico nacional, seja pela possibilidade de sua adoção como vertente filosófica seja pela necessidade de criticá-lo de modo profundo e responsável.
\end{abstract}

Palavras-Chave: Neoconstitucionalismo. Positivismo Jurídico. Póspositivismo. Neopositivismo.

\section{INTRODUÇÃO}

O direito positivo aparece no pensamento ocidental, no mínimo, ainda que de modo incipiente, desde Aristóteles, em sua concepção do justo legal (nomikón díkaion), em contraposição ao justo natural (ARISTÓTELES, 1996, p. 206). Nada obstante, é indubitável que foi a partir dos fenômenos histórico-políticos ligados às revoluções liberais e com o movimento iluminista, que terminaram por estabelecer as bases do Estado contemporâneo, que

\footnotetext{
${ }^{338}$ Mestrando em Direito pela Universidade Federal do Rio Grande do Norte - UFRN. Especialista em Direito Civil e Processual Civil pela UFRN. Advogado.
} 
o Positivismo Jurídico se firmou como uma concepção jusfilosófica quase que hegemônica, dominando a filosofia do direito do Século XIX e a primeira metade do século XX.

Pode-se afirmar que as críticas mais acirradas ao positivismo jurídico se iniciaram com Lon Fuller, após a publicação do seu ensaio The law in quest of itself em 1940, atingindo seu auge com o famoso debate entre H. L. A. Hart e Ronald Dworkin, iniciada com o seminário de1967 The Model of Rules I, em que este último critica o positivismo daquele (SHAPIRO, 2007, p. 1), promovendo uma guinada na filosofia do direito a partir da segunda metade do século XX.

Diante desse cenário, o discurso de muitos juristas, especialmente os brasileiros, passaram a afirmar como truísmo que o pós-segunda guerra mundial representou o fracasso político do positivismo (BARROSO, 2006, p. 20) e que, com a redemocratização e a consolidação dos novos Estados constitucionais europeus, tal corrente filosófica restou falida, sendo totalmente imprestável, remanescendo apenas seu valor histórico ${ }^{339}$, inaugurando um novo cenário jusfilosófico intitulado Pós-positivismo, que serve de base para o neoconstitucionalismo ${ }^{340}$.

No Brasil, o antipositivismo ganhou muitos adeptos das teses defendidas pelo precitado Dworkin e, sobretudo, por Robert Alexy, que advogam a existência de princípios dotados de normatividade e carga eminentemente axiológica nas constituições atuais, constituindo verdadeiros elementos de porosidade para a incorporação de valores no ordenamento jurídico, refutando por completo a tese da separação entre o direito e a moral, axioma basilar da teoria juspositivista.

Todavia, este discurso importado tem sido abordado distorcidamente por parte da doutrina pátria, sobretudo aquela que assevera a morte do positivismo, sem muito compromisso em discutir se ele realmente é ou não conformável com os ordenamentos jurídicos contemporâneos, se propõe um modelo de jurisdição injusto e ainda se é politicamente indesejado.

\footnotetext{
${ }^{339} \mathrm{Na}$ doutrina estrangeira podemos ver certa semelhança, por exemplo, em Carla Faralli (2006), que dedica todo seu livro com o sugestivo título de Filosofia Contemporânea do Direito sem tecer qualquer comentário sobre o positivismo pós-hartiano.

$340 \mathrm{O}$ termo neoconstitucionalismo não tem um sentido unívoco, mas incorpora diversas posturas teóricas geralmente associadas ao segundo pós-guerra que criticam o positivismo até então dominante, que, "no Brasil acabou por institucionalizar uma recepção acrítica da jurisprudência dos valores, da teoria da argumentação de Robert Alexy e do ativismo judicial norte-americano" (STRECK, 2013, p. 12).
} 
Essa confusão se dá muito em razão da antonomásia gerada em torno do próprio termo positivismo jurídico, que em geral é interpretado de modo reducionista como sendo uma corrente que nega a existência da moral no direito.

Propõe-se, pois, neste estudo, demonstrar que tal conclusão acerca do positivismo jurídico está equivocada, uma vez que ele ainda é estudado com abordagens distintas e tido como posição filosófica de jusfilósofos das mais diferentes nacionalidades.

Impende ressaltar, neste momento, que não se tem o afã de discutir o mérito do positivismo, mas tão somente se tem a pretensão de expor as correntes positivistas hodiernas, ignoradas - intencionalmente ou não - por boa parte dos juristas brasileiros, que se desenvolveram até com certa profusão após H. L. A. Hart.

Para tanto, o texto abordará o caminho histórico-filosófico do positivismo jurídico desde as suas origens para expor os fundamentos filosóficos do positivismo descritivo, especialmente dos maiores expoentes desta corrente, a saber John Austin, Hans Kelsen e H. L. A. Hart. Feito isto, apresentar-se-á resumidamente a crítica ao positivismo realizada por Ronald Dworkin, para, então, expor que há mais de uma corrente sobrevivente do positivismo jurídico.

Ao final, sem ter a pretensão de afirmar a superioridade das correntes positivistas sobre as não positivistas, credita-se ser essencial aos filósofos do direito brasileiros não apenas reconhecer, mas também criticar racionalmente as correntes neopositivistas, dando fim ao discurso velado que (não) gira em torno do assunto.

\section{ESCLARECIMENTO PRÉVIO: O SIGNIFICADO DO TERMO "POSITIVISMO JURÍDICO"}

O termo positivismo jurídico é utilizado com certa prodigalidade e pouca precisão, não parecendo claro que todos atribuem o mesmo significado a este nome. Por isto, pretende-se explicar em abstrato o seu conteúdo, para, em seguida, delimitar o que se chamará de positivismo jurídico nas próximas linhas, sendo este entendimento pressuposto lógico para a leitura do restante do artigo.

Norberto Bobbio (2006, p. 133-134), em obra clássica sobre o tema, apresenta uma classificação precisa, sob a qual o positivismo pode ser distinguido sob três aspectos, quais sejam: a) como modo de abordar o estudo do direito; b) como teoria do direito; e c) como ideologia do direito. 
O primeiro aspecto leva em conta a separação entre Direito e Moral, mais especificamente a diferenciação entre juízo de fato e juízo de valor. O juspositivismo, por pretender ser ciência, propõe uma abordagem avalorativa do direito, na medida em que ele é considerado como um fato social, sendo papel do jurista "estudar o direito do mesmo modo que o cientista estuda a realidade natural, isto é, abstendo-se absolutamente de formular juízos de valor" (BOBBIO, 2006, p. 131). Isso implica dizer que a validade do direito, pelo menos $a$ priori, é formalista, prescindindo da análise de seu conteúdo, sendo que a "afirmação da validade de uma norma jurídica não implica também na afirmação do seu valor" (BOBBIO, 2006, p. 131).

No que toca ao segundo aspecto, do positivismo como teoria, significa o reconhecimento das seguintes teses: a) teoria do coação, pela qual o direito se caracterizaria pela coatividade; b) teoria da legislação como fonte preeminente do direito; c) teoria imperativista do direito, que considera a norma um comando; d) teoria da coerência e completude, pela qual se nega a existência de lacunas e antinomias; e) teoria da interpretação mecanicista, pela qual a atividade do intérprete é meramente declarativa.

Por fim, como ideologia do direito, o positivismo aparece como uma proposta ética, defendendo a aplicação da teoria da obediência absoluta da lei enquanto tal, já que com o advento do Estado moderno a lei seria a única fonte do Direito e o Direito estatal-legislativo o único ordenamento normativo.

Os referidos aspectos são independentes entre si, podendo coexistir ou subsistir isoladamente, não sendo necessário que a utilização do termo positivismo jurídico implique numa referência a todos eles, mas, ao contrário, pode-se utilizá-lo para se referir a apenas de um deles. É perfeitamente possível, assim, ser um positivista metodológico sem ser um positivista teórico e/ou ético.

O presente artigo tem como enfoque tão somente a primeira acepção do termo, mas se faz necessário relatar também o seu surgimento e solidificação como teoria do direito no afã de localizar historicamente as críticas a ele empreendidas e a resposta a elas.

\section{OS PRECURSORES DO POSITIVISMO JURÍDICO}

\subsection{O PONTAPÉ: JEREMY BENTHAM}


A despeito da ausência de codificação, foi na Inglaterra onde o positivismo jurídico primeiro conseguiu se firmar como teoria jurídica, muito pela influência hobbesiana de respeito aos imperativos emanados pela autoridade. Neste contexto, surge o pensamento de Jeremy Bentham, que viveu entre 1748 e 1832, e ainda no século XVIII começou a pincelar o que seriam as bases desta doutrina.

O referido jusfilósofo teve o mérito de trazer a teoria imperativista para o campo jurídico. Ele definiu como prescrição jurídica aquela decorrente de um comando autoritário imposto pela vontade do soberano a uma determinada comunidade, em contraposição ao sistema da common law vigente à sua época, que defendia uma produção eminentemente judiciária do direito.

Bentham dividia a teoria jurídica em duas vertentes, quais sejam a expository jurisprudence, responsável por realizar a descrição objetiva do direito positivo tal como ele é, e a censorial jurisprucence, que visa estabelecer as regras jurídicas essenciais a todos ordenamentos jurídicos, de acordo com o princípio da utilidade. Nas palavras do professor Thomas Bustamante (2015, p. 311),

A teoria jurídica "censória" é, como o próprio Bentham expressa, uma "teoria da legislação" que pretende servir de "modelo" para o legislador ao revelar os princípios políticos que mais se coadunam como o princípio da utilidade.

Não obstante o pioneirismo e sua importância para a consolidação do Positivismo Jurídico, ainda não foi com ele que o positivismo meramente descritivo nasceu. Isso porque ele, assim como os jusnaturalistas, baseava-se na possibilidade de estabelecimento de uma ética objetiva, da qual poderia se deduzir os demais comportamentos humanos. Seu único ponto de divergência com estes é que o princípio ético fundamental não deflui na própria natureza humana, mas sim do fato empiricamente comprovado de que o homem busca sempre o que é mais útil para si (BOBBIO, 2006, p. 92).

Some-se a isso o fato de Bentham exaltar a censorial jurisprudence, sendo esta o aspecto mais marcante de sua filosofia jurídica, e, portanto, imprescindível ao projeto político por ele intentado, e que estava por detrás de toda sua teoria jurídica, qual seja o de abolir o sistema da common law na Inglaterra, que ele reputava como sendo irracional, arbitrário e que gerava insegurança jurídica, em prol da codificação (BUSTAMANTE, 2015, p. 311).

Corroborando a posição ora esgrimida, Frederick Schauer (2010, p. 21) afirma que 
distinguishing law as it is from aw as it ought to be. In terms of motivation - which is of course not the same as logical or conceptual priority - there is little doubt that Bentham's conceptual positivism was developed for normative reasons.

\title{
3.2 A CONSOLIDAÇÃO: JOHN AUSTIN
}

Pode-se dizer que apenas com John Austin ${ }^{341}$, o mais célebre pupilo de Bentham, o positivismo descrito pode ser levado a cabo, ao abandonar quase que totalmente a censorial jurisprudence e o componente ético utilitário como critério racional para propor reformas políticas e criticar a common law, na medida que reduziu todo direito ao direito legislativo.

Em Austin ainda se verifica a autoridade como elemento conceitual da disposição jurídica (comando do soberano aos súditos). No entanto, diferentemente de Bentham, seu interesse não era na ciência da legislação e sim na jurisprudência geral, que estudava o direito positivo comum a todos os ordenamentos jurídicos (BOBBIO, 2006, p. 102). Austin, portanto, preocupou-se em criar um sistema jurídico, pautado no seu conceito de soberania, que atribui a obrigatoriedade do direito ao seu caráter sancionador (OLIVEIRA, 2011, p. 27), pouco se importando com o conteúdo deste sistema. E é por esta razão que Bobbio (2006, p. 118) afirma que ele era um jurista técnico e um conservador, enquanto Bentham era um filósofo e um radical.

O objeto de sua teoria jurídica é tão somente o direito positivo puro, ou seja, apenas o direito posto pelo Estado. Daí ressai o afastamento entre a normatividade e a teoria do direito, tornando-se esta meramente descritiva. É com essas razões que Gianluigi Palombella (2005, p. 122) aduz que

\begin{abstract}
Austin inaugura uma corrente (da chamada jurisprudence, teoria do direito) que fará escola na Inglaterra: é a chamada teoria analítica, baseada em critérios lógicodescritivos com vista à identificação das categorias e dos conceitos jurídicos a que se pode chegar não por meio de dedução racionalista, mas de dedução empírico-factual que possibilite abstraí-los, também como métodos comparativos, dos ordenamentos jurídicos positivos.
\end{abstract}

Em outras palavras, só com as ideias difundidas por John Austin o positivismo jurídico passou a ser verificado como uma teoria do direito propriamente dita, na perspectiva apresentada adrede por Norberto Bobbio.

\footnotetext{
${ }^{341}$ Para fins ade localização temporal, está-se falando aqui já em meados do século XIX, dado que ele publicou um único livro em vida, em 1832, intitulado The province of jurisprudence determined, sendo que todo o resto de sua obra foi compilada após sua morte, o que só ocorreu em 1859.
} 


\subsection{O ÁPICE: HANS KELSEN}

Se Austin inaugurou o positivismo descritivo, foi apenas com a teoria pura do jurista austríaco Hans Kelsen que o positivismo descritivo chegou ao seu cume, a partir da plena separação entre o conhecimento jurídico e do conhecimento não jurídico, intentando fazer do Direito uma ciência. Para tanto, ele credita à chamada norma fundamental a legitimidade de todo o sistema jurídico, sendo que todas as prescrições jurídicas têm nela sua origem comum, sendo a fonte autorizadora de criação do Direito.

A norma fundamental é o ponto fulcral da teoria kelseniana na medida que, além de conferir a unidade e fomentar a completude do ordenamento jurídico, ela fundamenta a própria normatividade do direito. Isto é, diferentemente do que pregava Austin, para Kelsen (2003, p. 215) uma disposição normativa não deriva sua existência de sua facticidade. Para ele uma norma é válida porque sua produção foi autorizada pela norma fundamental e não por ter sido produzida pelo soberano (legislador).

Dito de outro modo, em Kelsen, a descrição do objeto de estudo - o Direito - é o cerne da sua teoria, de modo que seu isolamento deve ser absoluto. A tese da fonte do direito, assim como a da separabilidade entre Direito e moral, não é resultado de uma abordagem interpretativa ou construtiva, nem tampouco como uma opção motivada por ideais políticos ou uma ética objetiva fundante (BUSTAMANTE, 2015, p. 314).

\subsection{O DECLÍNIO: H. L. A. HART}

A partir da breve exposição sobre as teorias de Kelsen e de Austin, percebe-se uma aproximação clara entre ambas: as duas consideram a gênese das disposições jurídicas como traço distintivo do que tenha conteúdo jurídico e, consequentemente, do que seja Direito, com a diferença que Austin reconhece a identidade do Direito a partir de ordens imperativas de um soberano ao passo que Kelsen substitui a ideia de soberano pela de norma fundamental.

Herbert Lionel Adolphus Hart, no seu livro de 1961 "O conceito de direito”, destacouse por criticar a teoria imperativista (presente em Austin e Bentham), bem como a vagueza da fonte legitimadora do direito kelseniana, transferindo a problemática da interpretação judicial da mera subsunção para a discricionariedade do juiz, descartando quase que por completo o elemento da coerção para dar espaço ao que o jurista chama de ponto de visto interno. 
Para Hart a legitimidade ${ }^{342}$ do sistema jurídico se encontra em um momento prévio à criação das normas jurídicas, quando os indivíduos que integram dada sociedade reconhecem e acordam, mediante o recurso a costumes, a autoridade das disposições normativas (COLEMAN, 2001, p. 115). Esta autorização costumeira é, portanto, concedida pelos próprios destinatários das normas jurídicas e legitima todo o ordenamento jurídico. Ele deu a ela o nome de regra de reconhecimento.

Em outras palavras, a teoria hartiana prega que a normatividade é decorrente da aceitabilidade por parte da comunidade jurídica, que convencionam os aspectos de validade para uma norma ser considerada jurídica. A regra de reconhecimento é, assim, uma prática, um costume, que pode ser observada e reconhecida.

Daí ressai clara a diferença entre a sua teoria e a dos seus predecessores. Com Austin e Bentham a divergência se dá no critério de validade do Direito, já que estes têm como pressuposto a obediência dos súditos aos comandos emanados pelo soberano enquanto Hart fundamenta na sobredita regra de reconhecimento, ao passo que a diferença com Kelsen é que este pressupõe a existência da norma fundamental, enquanto para Hart a regra de reconhecimento pode ser empiricamente verificável.

Pode-se afirmar que Hart acata as teses basilares do positivismo da separação entre direito e moral ${ }^{343}$ e das fontes sociais ${ }^{344}$. No entanto, ele deu um novo aporte ao positivismo ao desenvolver a diferenciação entre ponto de vista externo e interno.

Conforme defendido pelo autor, é possível que as regras de um sistema normativo sejam analisadas sob dois aspectos, um externo e um interno. Aquele diz respeito à situação em que determinado indivíduo é um mero observador externo de determinado sistema jurídico, portanto, ele próprio não participa daquele sistema como tampouco aceita as regras dele. Um exemplo dado pelo próprio Hart $(1994,114)$ de uma situação de ponto de vista externo é a afirmação "Na Inglaterra reconhecem como Direito...”. Neste caso há um "observador que

\footnotetext{
${ }^{342}$ Com a instituição da regra de reconhecimento, Hart intenta, ainda que de modo incipiente, formar uma teoria do direito que seja comprometida com as questões relativas à legitimidade da decisão tomada nos diversos níveis do poder estatal (Legislativo, Executivo ou Judicial), o que não estava presente nas teorias positivistas de então como aponta Lênio Streck (2013, p. 16).

343 O posicionamento do autor fica muito evidente quando da leitura do seu livro "O conceito de direito", no qual ele considera o positivismo jurídico "com o significado da afirmação simples de que não é em sentido algum uma verdade necessária que as leis reproduzam os satisfaçam certas exigências da moral, embora de fato o tenham frequentemente feito" (HART, 1994, p.202).

344 Tanto é assim que Scott J. Shapiro (2007, p. 6) assevera que Dworkin credita a Hart o conhecimento do direito não pelo seu conteúdo, mas pela sua origem: "The law of a community can be identified and distinguished by specific criteria, by tests having to do not with their content but with their pedigree or the manner in which they were adopted or developed".
} 
registra ab extra o facto de que um grupo social aceita tais regras" (HART, 1994, 114). O exemplo é uma afirmação externa, logo manifestando o ponto de vista externo, pois expressa uma "linguagem natural de um observador externo ao sistema que, sem aceitar ele próprio a regra de reconhecimento desse sistema, enuncia o facto de que outros a aceitam" (HART, 1994, 114).

A seu turno, o ponto de vista interno é verificado quando o indivíduo ou as instituições - especialmente o Poder Judiciário - usam as regras do sistema, manifestando sua aceitação por elas. Neste caso, o exemplo dado por Hart $(1994,114)$ é a expressão "O direito dispõe que...". Esta última afirmação é chamada interna, manifestando o ponto de vista interno, porque "é naturalmente usada por quem, aceitando a regra de reconhecimento e sem declarar o facto de que é aceite, aplica a regra, ao reconhecer uma qualquer regra do sistema como válida (HART, 1994, 114).

Em suma, Hart apresenta também a possibilidade de uma norma só ser considerada válida se assim for reconhecida por seus aplicadores, promovendo uma virada para o ponto de vista interno, incorrendo, caso assim tratada, na impossibilidade de reconhecer como válido o Direito descrito por um observador externo como propõem Austin e Kelsen ${ }^{345}$. Com o ponto de vista interno Hart

convida a formular perguntas que estavam proscritas pelo rigorismo metodológico do positivismo descritivo, como a questão de se saber quando uma decisão que possa ser inferida das fontes do direito é "racional" ou razoável, ou quando se pode dizer que uma decisão está corretamente fundamentada. Como explica novamente MacCormick, essas perguntas são diuturnamente formuladas pelos juízes e demais operadores do direito que o manejam do ponto de vista interno, fazendo parte do leque de indagações que esses participantes do discurso jurídico naturalmente levantam em sua atividade prática. (BUSTAMANTE, 2015, p. 317)

Noutro pórtico, não se pode olvidar do posicionamento de Hart em relação à discricionariedade do intérprete, já que ao mesmo tempo constitui um afastamento com relação aos positivistas que lhe antecederam e também é um ponto colidente entre ele e Dworkin. Para Hart (1994, p. 335)

em qualquer sistema jurídico, haverá sempre certos casos juridicamente não regulados em que, relativamente a determinado ponto, nenhuma decisão em qualquer dos sentidos é ditada pelo direito e, nessa conformidade, o direito apresenta-se como parcialmente indeterminado ou incompleto. [...] Assim, em tais casos juridicamente

\footnotetext{
${ }^{345}$ A reviravolta para o ponto de vista interno pode ser considerada "um primeiro passo para a autodestruição do positivismo descritivo, já que ela exige que o direito seja compreendido por meio de um tipo de pensamento que vai muito além das ambições "descritivistas" ou puramente "conceituais" de autores como Austin, Kelsen e o próprio Hart” (BUSTAMANTE, 2015, p. 316).
} 
não previstos ou não regulados, o juiz cria direito novo e aplica o direito estabelecido que não só confere, mas também restringe, os seus poderes de criação do direito.

Para ele o juiz, nos chamados hard cases exerce sua discricionariedade para criar o Direito no caso concreto. Este reconhecimento da incompletude e da parcial indeterminabilidade do sistema jurídico e a consequente opção pela discricionariedade supõe o abandono do positivismo jurídico de Austin e Kelsen.

Do exposto, pode-se afirmar que ao buscar uma compatibilização da normatividade com o caráter empírico do dever, por meio do recurso ao ponto de vista interno, e a liberação da discricionariedade do juiz, Hart enfraquece a teoria positivista meramente descritiva e, igualmente, afasta-se da concepção positivista de uma teoria do direito, no modelo da divisão de Bobbio.

Em razão do ponto de vista interno, há quem proponha, inclusive, uma releitura do trabalho hartiano numa perspectiva não puramente descritiva, mas sim ética-normativa, sendo fonte de inspiração para filosofias jurídicas prescritivas atuais de um tom positivista que apresentam uma abordagem mais crítica para o Direito do que as versões descritivo-analíticas (CAMPBELL, 2011, p. 31), como veremos mais adiante.

O que é inegável é que a virada para o ponto de vista interno, que deu um certo caráter hermenêutico ao Direito, possibilitou a crítica de Dworkin ao positivismo, especificamente à teoria de Hart, o que será abordado no próximo tópico.

\section{O SUPOSTO FIM DO POSITIVISMO}

Em razão do suporte apenas a um sistema fechado de regras, o positivismo jurídico descritivo (como modo de abordar e como teoria do direito) passou a receber severas críticas, especialmente por propiciar decisões judiciais tão somente ancoradas numa razão instrumental, sem se preocupar com a sua legitimidade e/ou pretensão de correção. Deste modo, ele não privilegia a fundamentação racional do conteúdo da norma, já que esta se legitimaria pelo mero procedimento interno, pela gênese do direito (validade) - seja pela autoridade em Austin, pela norma fundamental de Kelsen ou pela regra de reconhecimento de Hart. Nos hard cases, por exemplo, não se teria uma fundamentação correta, o que faz Hart chegar a conclusão pela possibilidade decisionista de que o juiz pode decidir ao seu livre arbítrio caso o direito não seja suficiente para determinar o estado de coisas. 
Ronald Dworkin é, provavelmente, o jusfilósofo que mais se destacou na crítica ao positivismo jurídico convencional ${ }^{346}$. Sem querer se imiscuir profundamente na obra deste autor, pretende-se apenas pincelar sobre sua crítica ao positivismo, em razão de sua notória popularização, inclusive no Brasil.

De início, impende destacar as três principais teses que, para Dworkin, caracteriza o positivismo, quais sejam: a) $\mathrm{O}$ direito de determinada comunidade pode ser identificada e distinguida por um critério específico, por meio de testes que não dizem respeito ao seu conteúdo, mas pela sua gênese e a maneira que elas foram adotadas e desenvolvidas; b) $\mathrm{O}$ conjunto das regras válidas é exaustivo, de modo que, nos casos em que não houver regra específica para decisão (hard cases), não podendo ser decidido por mera aplicação da lei, o juiz deve decidir conforme sua discricionariedade; c) dizer que alguém tem uma obrigação legal é dizer que o caso dele se encaixa em uma hipótese legal que o obriga a fazer ou não fazer algo (SHAPIRO, 2007, p. 6-7).

A estas teses positivistas é que Dworkin vai lançar suas críticas no seu livro "Levando os direitos a sério", em que argumenta a não plausibilidade da discricionariedade na medida em que ignora os muitos casos de aporia e de lacunas. Para ele, o positivismo jurídico é um "modelo de e para um sistema de regras" (DWORKIN, 2002, p. 36) e, como tal, deve ser rejeitado, já que é imprestável para explicar a existência dos princípios. Os princípios são espécies normativas utilizada na argumentação das decisões judiciais, especialmente nos hard cases, e não funcionam sob a lógica do tudo ou nada, como as regras, de modo que os conflitos entre princípios será resolvido pelo recurso ao sopesamento, em que se verifica qual princípio é mais importante no caso concreto (DWORKIN, 2002, p. 39-42).

Para Dworkin (2002, p. 46), os princípios são uma realidade e "estão por toda a parte, à nossa volta”. Eles tornam falsa a tese positivista do Pedigree, ou seja, de que a validade das espécies normativas depende apenas da sua origem, uma vez que os princípios dependem, eventualmente, do seu conteúdo. Em outras palavras, na medida em que para o positivismo a gênese é bastante para tornar uma norma legal, ele não pode explicar a existência de princípios cujo reconhecimento legal pressupõe a percepção moral.

\footnotetext{
${ }^{346}$ É essencial memorar que muitas outras escolas legais não compactuam com os dogmas do positivismo jurídico analítico, tais como o realismo jurídico e a hermenêutica jurídica. Nada obstante, a crítica de Dworkin se popularizou mundialmente pelo seu debate com Hart, firmando bases para o chamado pós-positivismo, especialmente pela sua separação de regra e princípio, que ganhou muitos adeptos no Brasil. O próprio autor chegou a afirmar que sua tese é "um ataque geral contra o positivismo" (DWORKIN, 2002, p. 35).
} 
Por essa linha de raciocínio, a tese positivista do pedigree deve ser rejeitada por duas razões. Em primeiro lugar, os princípios jurídicos são, por vezes, cogentes simplesmente por causa de suas propriedades morais intrínsecas e não por causa de sua positivação. Em segundo lugar, mesmo quando esses princípios são positivados, não é possível formular uma regra estável extraída de um princípio com base apenas no fato de ser institucionalizado (SHAPIRO, 2007, p. 14).

A existência dos princípios resolve também o problema da discricionariedade deixada por Hart, na medida em que eles guiam e restringem o aplicador do direito quando estão diante dos hard cases e de situações de ausência de regras claramente aplicáveis.

Não é que Dworkin (2002, p. 50-51) negue a existência da discricionariedade quando do julgamento, mas, para ele, a discricionariedade válida é apenas a assim chamada discricionariedade fraca, na qual os julgadores devem exercer seu poder discricionário balizado pelas normas legais. Desse modo, aos juízes é vedado que ele vá além da lei, aplicando normas extralegais para resolver o caso. Refutando ambas, a discricionariedade e a tese genética do direito válido, Dworkin conclui pela rejeição do positivismo jurídico como uma teoria adequada da lei.

Em suma, pode-se afirmar que a dissonância de Dworkin em relação ao positivismo descritivo reside no fato de que para ele as decisões judiciais não podem ser legitimadas apenas formalmente pelo procedimento, mas sim pelo seu conteúdo, devendo ir além do recurso à validade. Assim, ele argumenta que o direito positivo assimilou conteúdo morais, sem, contudo, com eles se confundir. A absorção desses elementos morais se daria pela sua positivação em princípios, que seriam espécies normativas diferentes das regras, sendo que estas obedecem apenas à lógica do tudo ou nada, e possibilitariam uma fundamentação racional da decisão judicial, o que afastaria a discricionariedade do juiz.

O cenário de crise do positivismo jurídico foi intensificado quando as críticas contundentes de Dworkin se somaram à doutrina que prega a incompatibilidade do Positivismo Jurídico com o Estado Constitucional democrático contemporâneo pós-segunda guerra mundial, modelo este que promoveu uma reviravolta conteudística no Direito, abandonando a ideia de Estado - meramente - de Direito que tinha como princípio maior o da legalidade e possibilitara então a instalação de regimes totalitários em diversos países da Europa.

Fato é que aconteceu um movimento de trânsito do Estado de Direito formal para a formação de Estados constitucionalmente mais democráticos, eclodindo com a promulgação de novas constituições (por exemplo, a da França em 1946, Itália em 1947 e Alemanha em 1949), 
mais comprometidas com direitos fundamentais e valores democráticos, buscando "fazer democracia a partir do e pelo direito" (STRECK, 2013, p. 18). Este período ficou conhecido como neoconstitucionalismo.

No Brasil, uma parte da doutrina chegou a afirmar que o neoconstitucionalismo tem, necessariamente, como "marco filosófico" o pós-positivismo, este entendido como uma superação do positivismo jurídico (BARROSO, 2006, p. 19). Ocorre que essas vozes se baseiam no erro epistemológico, intencional ou não, de tentar uma aproximação umbilical entre neoconstitucionalismo e pós-positivismo. Ora, tais conceitos não são sinónimos, nem tampouco é este a principal característica daquele (STRECK, 2013, p. 21). É inegável que no novo constitucionalismo valores morais foram incorporados nas cartas magnas, como na brasileira de 1988, que, decerto, tem conteúdo axiológico bem maior do que na versão liberal de 1824 . Isto é um fato histórico, empiricamente verificável que, pelo menos a princípio, não fere de morte o positivismo jurídico.

O neoconstitucionalismo, na verdade, pode ser visto sob diferentes enfoques, a depender da matriz teórica do autor que trata do assunto (STRECK, 2013, p. 20). Ou seja, teorias de direito muito diversas entre si podem ser rotuladas como neoconstitucionalistas, inclusive defensoras do positivismo jurídico, mas não somente as antipositivistas ou pós-positivistas, como a precitada teoria de Ronald Dworkin.

\section{O NEOPOSITIVISMO}

A imprecisão epistemológica relatada acerca do termo neoconstitucionalismo redundou em um descomprometimento de parte da doutrina brasileira com o que restou do positivismo jurídico no período neoconstitucionalista. É inegável, nesta toada, a contraofensiva hartiana às críticas de Dworkin contida no célebre posfácio de sua obra "O conceito de Direito", publicado postumamente em 1994.

Em resposta às críticas, Hart enfatiza a utilidade do positivismo a partir de uma teoria descritiva, sem negar que, em algum momento, ela se ocupe dos elementos valorativos ou do ponto de vista interno. Para ele "uma descrição pode ainda continuar a ser uma descrição, mesmo quando o que é descrito constitui uma avaliação" (HART, 1994, p. 306).

Assim, Hart (1994, p. 330) mantém sua tese principal da separação entre direito e moral, sustentando que, malgrado possa haver entre eles pontos de convergência, não existe nenhuma 
conexão conceitual necessária, podendo haver uma norma válida que seja moralmente indesejável. Isso valeria também para a teoria dworkiana, já que não há garantias que os princípios eleitos pelo ordenamento sejam todos corretos, não havendo, assim, ligação obrigatória entre os princípios e a moral. Com isso, ele refuta a aceitabilidade moral da teoria principiológica, uma vez que um sistema de princípios pode ser mais imoral que um direito fundado em regras, a depender dos princípios eleitos.

Para que uma norma seja válida ela independe do seu conteúdo. Ou seja, o critério de identificação do direito pode ser moralmente neutro, embora não tenha que sê-lo. Pode ocorrer de a própria regra de reconhecimento de um sistema jurídica determine que só é válida a norma moralmente aceitável. Tal fato é bem exposto quando Hart (1994, p. 332) afirma que segundo a sua teoria

a existência e o conteúdo do direito podem ser identificados por referência as fontes sociais do direito (por exemplo, legislação, decisões judiciais e costumes sociais), sem referência a moral, excepto quando o direito assim identificado tenha, ele próprio, incorporado critérios morais para a identificação do direito.

Com tal assertiva, Hart (1994, p. 312) se assume um positivista moderado, dando cabo aos questionamentos acerca da separabilidade entre direito e moral e, ao mesmo tempo, em relação à tese do pedigree (fontes sociais). Isso porque ele reconhece que pode haver princípios morais e valores substantivos como critérios de identificação do direito em determinado ordenamento, desde que estejam incorporados expressamente na regra de reconhecimento como condição de validade das normas.

O posfácio, além de ter demonstrado a possibilidade de sobrevivência do positivismo (ao menos na primeira acepção do termo, segundo a precitada subdivisão feita por Bobbio), influenciou filósofos do direito dos mais variados países a advogarem diferentes teses positivistas. Sendo assim, pretende-se a seguir apresentar sinteticamente algumas versões do positivismo pós debate Hart/Dworkin, comumente chamadas de "neopositivistas"347.

\subsection{POSITIVISMO EXCLUSIVO}

\footnotetext{
${ }^{347}$ Anthony J. Sebok (1998, 267-268), cunhador do termo neopositivismo, considera que este teve como primeira fase a publicação de "O conceito de Direito" de Hart; a segunda fase foi a da crítica de Dworkin a Hart; e a terceira fase compreende todos os jusfilósofos que pretenderam responder as críticas de Dworkin, a partir e para além do trabalho de Hart.
} 
Os defensores do positivismo jurídico exclusivo (também chamado de positivismo duro ou não incorporacionista) - dentre eles talvez o mais proeminente seja Joseph Raz, pupilo de Hart e responsável pela edição do Posfácio de "O conceito do Direito" - têm como presmissa uma forte separação entre direito e moral, de modo que para tal corrente é impossível que a qualidade moral de um padrão normativo figure entre as condições identificadoras de seu status como uma norma legalmente válida.

Eles argumentam, então, que Hart cometeu um erro ao sugerir o contrário em seu posfácio. Para eles, as condições de validade jurídica devem se concentrar exclusivamente em fatores que nada têm a ver com o conteúdo (ou moral) da norma em questão, senão se pode acabar misturando questões de direito e de moralidade, contrariando o próprio objetivo primário de toda lei que é separar o que é direito do que é moral.

Também chamada de tese das fontes, o positivismo exclusivo acredita que o fato social só será uma norma válida exclusivamente em decorrência da autoridade de seu criador, seja este uma lei, um precedente judicial ou um costume (WALUCHOW, 2009, p. 2).

É importante pontuar que o positivismo excludente não refuta a possibilidade de as normas jurídicas absorverem conteúdos morais, nem mesmo que o intérprete se utilize da moralidade quando diante de uma norma que o autorize. No entanto, uma norma nunca poderá ser considerada válida tão somente pela análise de seu conteúdo moral. Do mesmo modo que uma norma nunca poderá ser considerada inválida meramente por ser considerada imoral, se ela foi derivada de uma fonte legítima.

Seguindo esta linha de raciocínio, Andrei Marmor (2006, p. 683) explica que o positivismo jurídico deve ser entendido como meramente descritivo e moralmente neutro. Por descritivo porque ele não pretende justificar ou legitimar qualquer aspecto substancial de si próprio. Por moralmente neutro dada a desnecessidade tanto de escolher uma posição sobre uma moral em particular quanto por ter de tomar decisões de cunho político.

Em resumo, pode-se dizer que para seus adeptos, por uma questão de necessidade conceitual, a validade jurídica de uma norma nunca pode depender da sua coerência com os princípios e valores morais.

\subsection{POSITIVISMO INCLUSIVO}


O Segundo modelo adota a mesma visão exposta na contraofensiva hartiana ${ }^{348}$ chamado de positivismo brando, moderado ou inclusivo, sendo calcado na tese da separabilidade, para a qual legalidade e moralidade são apenas separáveis, mas não necessariamente sempre estarão separados. Ele reconhece, portanto, a possibilidade de a regra de reconhecimento de um determinado ordenamento determinar como condição de validade jurídica a obediência a princípios morais.

De um lado, esta corrente nega que todas as normas estejam vinculadas a um exame material de verificação de validade, mas de outro rejeitam a impossibilidade de o direito realizar tal exame, o que os situa entre os adeptos de Dworkin e os positivistas exclusivistas.

A aproximação entre direito e moral para eles seria, então, eventual, e dependeria do que a regra de reconhecimento do ordenamento jurídico determinar como condição de validade, sendo a ela facultado o estabelecimento de testes morais de validade, ao determinar que uma norma só seria válida acaso ela obedecesse certos princípios morais.

A diferença entre os positivistas inclusivistas e os defensores da tese das fontes é acentuada, merecendo, pela clareza, que sejam repetidas as palavras do jusfilósofo e professor da Universidade de Chicago, Brian Leiter (2002, p. 356-357), a respeito da distinção:

Soft [inclusive] positivists interpret the Separation Thesis as involving only a modal, existential generalization of the following form: it is (conceptually) possible that there exists at least one rule of recognition, and thus one legal system, in which morality is not a criterion of legal validity. Hard [exclusive] positivists, by contrast, interpret the Separation Thesis as requiring a universal generalization of the form: for all rules of recognition, hence for all legal systems, it is not the case that morality is a criterion of legality, unless some content-neutral criterion makes it so. Soft Positivists interpret the Social Thesis as saying only that a society's rule of recognition is constituted by the social facts about how officials actually decide disputes; thus, for example, if it is the 'practice' or 'convention' of officials to decide disputes by reference to morality, then morality, in that society, is a criterion of legality. Hard Positivists, by contrast, interpret the Social Thesis as a constraint on the content of the Rule of Recognition, not simply on its existence conditions. Thus, for Hard Positivists the Social Thesis says not only that a rule of recognition is constituted by social facts (e.g. facts about the conventional practice among officials in resolving disputes) but also that the criteria of legal validity set out by any society's rule of recognition must consist in social facts (e.g. facts about pedigree or sources).

Do ponto de vista prático, os inclusivistas têm como paradigma o ordenamento jurídico dos Estados Unidos da América, onde é comum o recurso aos princípios e valores morais para resolução de conflitos, em especial dos casos difíceis. O próprio Hart (1994, p. 312) reconhece

\footnotetext{
${ }^{348}$ É de se destacar que o próprio Hart (1994, p. 312) afirma que ele adotava o positivismo muito antes do seu posfácio, de modo que só respondeu a crítica de Dworkin para reparar o erro que este cometera ao taxá-lo como seguidor de um "positivismo meramente factual", que só aceita como critério de validade jurídica as questões de pedigree.
} 
em emendas da Constituição Estadunidense, especificamente as que tratam do direito à religião e ao voto, como casos em que explicitamente a regra de reconhecimento incorpora a conformidade com princípios/valores como critério de validade jurídica, hipóteses em que é evidente a importância do conteúdo da lei, indo além de uma questão de pedigree.

Pode-se sintetizar o ideal inclusivista na seguinte sentença: é conceitualmente possível, mas de modo nenhum necessário, que a validade jurídica de uma norma depende da sua coerência com os princípios e valores morais.

\subsection{POSITIVISMO NORMATIVO}

Noutro pórtico, encontra-se o positivismo de autores como Tom Campbell e Jeremy Waldron, os quais rompem a barreira do positivismo descritivo, na medida em que se preocupam com o que o direito deve ser a partir de razões morais e políticas. Em uma palavra, pode-se dizer que esta vertente do neopositivismo sustenta a tese de que a determinação do que é o direito depende, obrigatoriamente, das considerações morais sobre o que ele deveria ser (MARMOR, 2006, p. 690).

Nesta perspectiva, o sistema jurídico se inicia com um argumento político-moral da missão do próprio direito para, só então, estabelecer-se critérios não morais de identificação de regras e princípios (WALDRON apud BUSTAMANTE, 2015, p. 323). Há, assim, um estabelecimento apriorístico de determinados valores que serão norte do referido sistema.

Pelo fato de prescrever o direito como este deve ser em uma sociedade democrática, a partir de valores morais, instituindo uma verdadeira agenda político-normativa, esta corrente ficou conhecida como positivismo normativo, prescritivo ou, ainda, ético.

Ao contrário do positivismo descritivo - neste incluídos os inclusivistas e os exclusivistas -, o positivismo normativo não pretende ser neutro e nem limita seu alcance à identificação da natureza do direito, mas, aproximando-se da censorial jurisprudence de Bentham, julgam haver princípios morais prévios que orientam o Direito.

Esses princípios morais, como a previsibilidade e a segurança jurídica, funcionam como verdadeiros vetores éticos do ordenamento jurídico, tendo, segundo Waldron (apud BUSTAMANTE, 2015, p. 325), a importante função de limitar o poder dos juízes já que estes não podem realizar valorações morais de questões éticas em nome da sociedade, o que é competência do poder legislativo.

Como bem explicado por Jeremy Waldron (2001, p. 421), 
a pretensão dos positivistas normativos é de que os valores associados ao direito - a
juridicidade e o estado de direito, em um sentido amplo - podem ser melhor
alcançados se a operação ordinária de tal sistema não exigir que as pessoas realizem
valorações morais para se saber o que o direito é.

O positivismo normativo, de um lado, ao imputar ao Parlamento a competência para discussão de assuntos políticos, valorativos, éticos e morais, intenta separar bem a função de criação e de aplicação do direito. De outro lado, embora reconheça que possa ocorrer a incorporação de razões morais para a identificação do direito - como sustenta o positivismo brando-, insurge-se contra esta possibilidade, defendendo que isso não deve ocorrer, sendo objetivo da doutrina que o entendimento e aplicação das normas se dê sem o recurso a juízos políticos e morais controvertidos (CAMPBELL, 2002, p. 306).

\section{CONSIDERAÇÕES FINAIS}

O positivismo jurídico foi a filosofia do direito dominante desde o século XIX, a partir da difusão das ideias de Bentham, vindo a se consolidar com os escritos de Austin, hegemonia que perdurou até pelo menos a metade do século XX, após atingir seu cume na teoria pura kelseniana.

A partir de então emergiram em seu desfavor duras críticas doutrinárias, especialmente relacionadas ao seu modo de abordar o direito como fato social, cuja validade prescinde de exames conteudísticos, o que criaria, em tese, uma barreira conceitual entre direito e moral.

Além da crítica teórica, no período pós-segunda guerra mundial imputaram ao positivismo a responsabilidade por propiciar a instalação de regimes de cunho totalitaristas, que fundamentavam sua legitimidade no legalismo exacerbado, sem qualquer preocupação axiológica, o que enfraqueceu sua conveniência política.

No entanto, a partir da obra "O conceito de direito" de Herbert L. A. Hart houve uma reviravolta na filosofia juspositivista, notadamente pela formulação do conceito de ponto de vista interno, segundo o qual a validade do direito é verificada diretamente por quem o aplica na prática, ou seja, por aqueles sujeitos que estão vivendo o direito, criando uma alternativa à visão até então predominante na qual o direito é descrito por um espectador fora do sistema. Com isso, Hart deu ares mais hermenêuticos ao direito, abrindo caminho, inclusive, às críticas a ele direcionadas. 
Ronald Dworkin, responsável por muitas delas, faz pelo menos três críticas contundentes a ele: a primeira é contra a tese do pedigree, de que a lei pode ser identificada pela maneira de sua criação (autoridade) e não pelo seu conteúdo; a segunda diz respeito a hipótese de discricionariedade do juiz em casos que não haja lei possível a ser aplicada; e, por fim, ataca a tese da obrigação, segundo a qual um indivíduo só tem uma obrigação legal quando assim o diga uma regra.

Para Dworkin, a validade das normas não se resume a uma questão de pedigree, mas também a uma análise substancial, de modo que o procedimento, por si só, não identifica o que é o direito. Ele afirma que o ordenamento jurídico se imiscuiu de valores e conteúdos morais, positivados sob a forma de princípios, espécie normativa diferente das regras.

Fato é que, a partir de então, popularizaram-se as correntes antipositivistas (póspositivistas), o que coincidiu, historicamente, com o período denominado de neoconstitucionalismo (novo constitucionalismo), movimento jurídico-político surgido no póssegunda guerra que propugna a revalorização e fortalecimento da Constituição, apontando para uma formação de uma nova cultura jurídica voltada para a efetivação dos direitos fundamentais.

Costuma-se no Brasil, até com certa assiduidade, incorrer na imprecisão semântica de afirmar que o antipositivismo (pós-positivismo) é sinônimo de neoconstitucionalismo, ou que aquele é a única base filosófica deste. Ocorre que, como demonstrado no presente trabalho, a oposição entre neoconstitucionalismo e positivismo jurídico é totalmente equivocada, tendo esta filosofia do direito sobrevivido com proficuidade, senão como ideologia ou como teoria, pelo menos como modo de abordar o direito.

Ou seja, há duas formas de se conceber no novo paradigma neoconstitucional, sobre cujas bases se apresentam as mais diferentes teorias do Direito: de um lado, o póspositivismo/antiposisitivsmo, que visa à superação do positivismo; de outro, o neopositivismo, que ainda, de alguma maneira, aposta no positivismo.

Aliás, não é difícil ver que o neopositivismo é realidade, já que se propagou com difusão nos mais variados países após as críticas de Dworkin a Hart, especialmente após os anos 70, consolidando-se ainda com mais rigidez com a publicação do posfácio de "O conceito do direito", em 1994.

Hoje, existem pelo menos 3 subdivisões do neopositivismo: o positivismo excludente, o inclusivo e o normativo. O positivismo excludente apregoa que o conteúdo dos critérios de validade seja delimitado por fontes sociais, nunca podendo incorporar valores ou quaisquer elementos morais. A seu turno, o positivismo inclusivo faz tão somente a exigência de os 
fundamentos dos critérios de validade serem fundados em um fato social, que é justamente a convenção entre as autoridade que criam as normas, mas os referidos critérios podem fazer referência a exigências ético-morais desde que assim preveja a regra de reconhecimento. Por fim, o positivismo normativo defende que é desejável que as leis sejam facilmente identificáveis como fontes sociais não controversas. Neste afã, visa restringir o seu conteúdo moral, uma vez que este, se incorporado ao direito, prejudicaria sua clareza e dificultaria uma aplicação objetiva. Noutro aspecto, esta doutrina busca um novo aporte em Bentham, preocupando-se não com o que é o direito, mas primordialmente com o que o direito deveria ser, daí ressaindo seu caráter ético-prescritivo.

É de se concluir, portanto, que o juspositivismo ainda vive, sendo essencial que as correntes neopositivistas estejam presentes no debate jurídico brasileiro dada a plena possibilidade de sua adoção como filosofia do direito e sua importância na compreensão das práticas jurídicas hodiernas. Qualquer oposição a ele carece de uma crítica aprofundada, bem mais elaborada do que a falácia sobre sua superação que parte da doutrina brasileira adotou como truísmo.

\section{REFERÊNCIAS}

ARISTÓTELES. Ética a Nicômaco. São Paulo: Nova Cultural, 1996.

BARROSO, Luís Roberto. Neoconstitucionalismo e constitucionalização do direito: o triunfo tardio do direito constitucional no Brasil. Revista da ESMEC: Themis, Fortaleza, v. 4, n. 2, p. 13-100, jul./dez. 2006. Disponível em: <http://portais.tjce.jus.br/esmec/wpcontent/uploads/2008/10/themis_v4_n_2.pdf>. Acesso em: 01 de ago. 2016.

BOBBIO, Norberto. O Positivismo jurídico: Lições de Filosofia do Direito. São Paulo: Ícone, 2006.

BUSTAMANTE, Thomas. A breve história do positivismo descritivo. O que resta do positivismo jurídico depois de H. L. A. Hart?. Revista Novos Estudos Jurídicos - Eletrônica, v. $20, \quad$ n. $1, \quad$ p. 307-327, jan./abr. 2015. Disponível em: <http://siaiap32.univali.br/seer/index.php/nej/article/view/7204/4100>. Acesso em: 20 jul. 2016.

CAMPBELL, Tom. Rewriting Hart`s Postscript: Thoughts on the development on the legal positivism. Revista Problema: Anuario de filosofia y teoria del derecho. n. 5, p. 23-52, out. 
2011. Disponível em: <http://revistas.juridicas.unam.mx/index.php/filosofiaderecho/article/view/8108/10055>. Acesso em: 19 jul. 2016.

El sentido del positivismo jurídico. Trad. Ángeles Ródenas. Doxa: Cuadernos de filosofía del derecho. Alicante, n. 25, p. 303-331, 2002. Disponível em: <http://www.cervantesvirtual.com/obra/el-sentido-del-positivismo-jurdico-1/>. Acesso em: 28 jul. 2016.

COLEMAN, Jules. Incorporationism, conventionality, and the practical difference thesis. In: COLEMAN, Jules (Org.). Hart's Postscript: Essays on the postscript to the concept of the law. Oxford: Oxford University Press, 2001, p. 99-147.

DWORKIN, Ronald. Levando os direitos a sério. São Paulo: Martins Fontes, 2002.

FARALLI, Carla. A filosofia contemporânea do direito: temas e desafios. Tradução de Candice Premaor Gullo; Revisão da tradução de Silvana Cobucci Leite. São Paulo: WMF Martins Fontes, 2006.

HART, H. L. A. O Conceito de Direito. 3. Ed. Lisboa: Fundação Calouste Gulbenkian, 1994.

KELSEN, Hans. Teoria pura do direito. São Paulo: Martins Fontes, 2003.

LEITER, Brian. Legal Realism, Hard Positivism, and the Limits of Conceptual Analysis. In: COLEMAN, Jules L (Org.). Hart's Postscript: Essays on the postscript to the concept of the law, Oxford University Press, 2001, p. 355-370.

MARMOR, Andrei. Legal Positivism-Still Descriptive and Morally Neutral. Oxford Journal of Legal Studies, v. 26, n. 4, p. 683-704, 2006. Disponível em: <http://scholarship.law.cornell.edu/cgi/viewcontent.cgi?article=2569\&context=facpub>. Acesso em: 20 jul. 2016.

OLIVEIRA, Carlos Frederico Delage Junqueira de. Identidade do Direito, Individualização de Disposições Jurídicas e o Caráter Peremptório das Razões para a Ação. 2011; 161 f.Tese (doutorado em Direito) - Departamento de Direito da PUC. Pontifícia Universidade Católica, Rio de Janeiro.

PALOMBELLA, Gianluigi. Filosofia do direito. Tradução de Ivone C. Benedetti; Revisão técnica de Ari Solon. São Paulo: Martins Fontes, 2005. 
SCHAUER, Frederick, Positivism before Hart. University of Virginia Public Law and Legal Theory Research Paper Series, n. 01, p. 1-34, jan. 2010. Disponível em: <http://papers.ssrn.com/sol3/papers.cfm?abstract_id=1512646>. Acesso em: 21 jul. 2016.

SEBOK, Anthony. Legal positivism in American Jurisprudence. Cambridge: Cambridge University Press, 1998.

SHAPIRO, Scott J. The "Hart-Dworkin" debate: a short guide for the perplexed. University of Michigan public law working paper, n. 77, p. 1-55, mar. 2007. Disponível em: <http://papers.ssrn.com/sol3/papers.cfm?abstract_id=968657>. Acesso em: 25 jul. 2016.

STRECK, Lênio Luiz. O constitucionalismo no Brasil e a necessidade da insurgência do novo: de como o neoconstitucionalismo não supera o positivismo. Revista do CEJUR/TJSC: Prestação Jurisdicional, Florianópolis, v. 1, n. 01, p. 11-28, dez. 2013. Disponível em: <https://revistadocejur.tjsc.jus.br/cejur/article/view/23/27>. Acesso em: 20 jun. 2016.

WALDRON, Jeremy. Normative (or Ethical) Positivism. In: COLEMAN, Jules (Org.). Hart's Postscript: Essays on the Postscript to "The Concept of Law". Oxford: Oxford University Press, 2001, p. 410-433.

WALUCHOW, W. J. Four Concepts of Validity: Reflections on Inclusive and Exclusive Positivism. In: ADLER, Matt; HIMMA, Ken (Org.). The rule of recognition and the United States Constitution. Oxford: Oxford University Press, 2009. Disponível em: <http://papers.ssrn.com/sol3/papers.cfm?abstract_id=1296840>. Acesso em: 01 ago. 2016.

\title{
THE SURVIVAL OF LEGAL POSITIVISM
}

\begin{abstract}
The research aims to analyze if the advent of neoconstitutionalism resulted in the total overcoming of legal positivism, as part of the brazilian doctrine often claims. Much of this problem is linked to the semantic vagueness that surrounds the two terms: legal positivism and neoconstitutionalism. Properly marking the use of both expressions, this paper synthetically exposes the evolution of this philosophical movement by the ideas of its main advocates, and, after that, discusses the criticism aimed at it by Ronald Dworkin, the postpositivism precursor. It demonstrates that different inclination philosophers confronted Dworkin, intending to adapt that philosophy of law to the current historical context, originating a school of law known as
\end{abstract}


neopositivism. It concludes, therefore, that legal positivism survives in the neoconstitucional period and should be prestigious in the national legal debate, either because of the possibility of its adoption as a philosophical current or for the need to criticize it in a deep and responsible way.

Keywords: Neoconstitucionalism. Legal Positivism. Post-positivism. Neopositivism. 